American Journal of Animal and Veterinary Sciences 6 (4): 171-175, 2011

ISSN 1557-4555

(C) 2011 S. Hamedi et al., This open access article is distributed under a Creative Commons Attribution

(CC-BY) 3.0 license

\title{
Histological Changes of Small Intestinal Mucosa of Cocks Due to Sunflower Meal Single Feeding
}

\author{
${ }^{1}$ Hamedi, S., ${ }^{2}$ M. Rezaian and ${ }^{3}$ T. Shomali \\ ${ }^{1}$ Department of Basic Sciences, \\ Faculty of Veterinary Medicine, \\ Islamic Azad University-Karaj Branch, Karaj, Iran \\ ${ }^{2}$ Department of Basic Sciences, Division of Histology, \\ Faculty of Veterinary Medicine, University of Tehran, Tehran, Iran \\ ${ }^{3}$ Department of Basic Sciences, \\ Division of Pharmacology and Toxicology, \\ School of Veterinary Medicine, Shiraz University, Shiraz, Iran
}

\begin{abstract}
Problem statement: This study was conducted to evaluate histological changes of small intestine of adult cocks due to sunflower meal single diet. Approach: Twenty adult cocks were randomly allocated into two equal groups (experimental and control); control group fed with basal diet, while Sunflower meal supplemented to basal diet of experimental group gradually with the ratio of 30, 45, 60, 75 and 90 during a week and 100\% during the next week. At the end of the period all animals sacrificed and $6-\mu \mathrm{m}$ transverse sections from the middle parts of duodenum, jejunum and ileum prepared and stained with HandE and PAS. Villus length, villus width, crypt depth, villus length/crypt depth ratio and goblet cell number per unit area were measured. Chemical composition of sunflower meal and basal diet determined and metabolizable energy of sunflower meal and basal diets measured. Data analyzed by student's t test. Results: Crude fiber and crude protein of sunflower meal were $81 \%$ and $44 \%$ higher than basal diet respectively, while both AME and TME were about $40 \%$ lower in sunflower meal compared to basal diet. No difference observed between $\mathrm{AME}$ and $\mathrm{AME}_{\mathrm{n}}$ or TME and $\mathrm{TME}_{\mathrm{n}}$ in both diets. In duodenum of birds in experimental group, a significant decrease in villus length and villus length/crypt depth ratio and a significant increase in number of goblet cells observed while in jejunum there was only a significant increase in goblet cell number. In ileum of these birds number of goblet cells increased while villus length, villus width and villus length/crypt depth ratio decreased significantly compared to control group. Conclusion: Single feeding with sunflower meal can adversely affect morphological parameters of small intestinal mucosa of cocks especially in ileum, which may be due to its low energy and/or high fiber content.
\end{abstract}

Key words: High fiber sunflower meal, histology, small intestine, cock, energy content

\section{INTRODUCTION}

Sunflower (Helianthus annus) could be harvested two or three times a year in tropical areas and is a good alternative for oil producers and feed mill sector (Vieira et al., 1992). Although sun flower meal is a well established and relatively inexpensive source for poultry diets, its use is limited by variations in its chemical composition as well as two restricting characteristics that are high fiber/low energy ratio and low lysine content (Senkoylu and Dale, 1999).
Diet composition can change gut morphology and subsequently absorptive capacity of the gut which in turn affects animal performance. In a study performed by Kalmendal et al. (2011), inclusion of fibrous residue of cold-pressed black-and-white sunflower seeds at 10 , 20 and $30 \%$ of the diets of broiler chickens, mediated significant linear increases in ileal digestibility of fat and protein and significant linear decreases in ileal digestibility of dry matter, ash and energy. Moreover, fibrous residue of sunflower seeds inclusion resulted in significant linear reductions of villus height, thickness

Corresponding Author: Somayeh Hamedi, Department of Basic Sciences, Division of Histology, Faculty of Veterinary Medicine, Islamic Azad University-Karaj Branch, Karaj, PO Box: 31485-313, Iran Tel: +98 9123332207

Fax: +98 2614418156 
of muscularis mucosa and the circular and longitudinal layers of muscularis in the jejunum. Crypt depth and submucosal thickness were not affected. Weight gain increased linearly with inclusion of fibrous residue of sunflower seeds although feed conversion was negatively affected by high percentage of fibrous residue of sunflower seeds. While Vieira et al. (1992) reported that egg production, egg weight and egg shell quality are not adversely affected by adding graded levels (13.5, 27 and 40.5\%) of sun flower meal in layer diets; Rezaei and Hafezian, (2007) demonstrated that using sun flower meal as $15 \%$ of the diet, significantly decreases feed consumption, egg production and weight accompanied by increases in feed conversion ratio of laying hens.

Regarding the diversity in the findings of previous investigations on broilers and layers, the purpose of the present study was to clarify possib41le effects of using sun flower meal as the single feed on morphological features of duodenal, jejunal and ileal mucosa of adult cocks; which usually used for calculations of energy requirements in poultry, since have no appreciable growth or production.

\section{MATERIALS AND METHODS}

Experimental design and determination of metabolizable energy of diets: Twenty Rhode Island Red cocks, 70 weeks of age, from the same population, were housed individually in metabolic cages in a temperature-controlled room $\left(24 \pm 2^{\circ} \mathrm{C}\right)$ with $16: 8 \mathrm{~h}$ light/dark cycle. Each cage was fitted with an individual feeder and a nipple drinker. A fixed aluminum tray was placed under each cage to allow collecting of droppings separately. All birds had free access to a maintenance diet and tap water during oneweek adaptation period. Prior to starting the experiment, all birds were fasted for $24 \mathrm{~h}$ to ensure that no feed residues remained in their alimentary tracts and then randomly divided into two equal groups and fed with sunflower meal as Experimental Group (EG) or basal diet with the composition mentioned in Table 1 as Control Group (CG) for 14 days. Adding sunflower meal to the EG diet was gradually and by inclusion of $30,45,60,75$ and $95 \%$ sunflower meal to the basal diet during one week, $24 \mathrm{~h}$ of fasting and then feeding with $100 \%$ of sunflower meal during the next week followed by $24 \mathrm{~h}$ of fasting. Animals were weighed daily during the experiment.

Chemical composition of sunflower meal and basal diets determined (AOAC, 1990) moreover, metabolizable energy of sunflower meal and basal diets assayed as follows: droppings voided during the second week were collected, weighed and frozen in $-20^{\circ} \mathrm{C}$. Before analysis, samples dried at $80^{\circ} \mathrm{C}$ oven overnight. Gross energy of meals and excreta were determined by a Parr4 Model 1241 adiabatic oxygen bomb calorimeter. Nitrogen correction was carried out using an $8.73 \mathrm{kcal}$ per nitrogen retained. Total Intake of feed Energy (IE) and nitrogen (IN) and dropping energy (Fecal Energy + Urinary Energy) and nitrogen (Fecal Nitrogen + Urinary Nitrogen) were measured for each bird. Values of Apparent Metabolizable Energy (AME), nitrogen-corrected Apparent Metabolizable Energy $\left(\mathrm{AME}_{\mathrm{n}}\right)$, True Metabolizable Energy (TME) and nitrogen-corrected True Metabolizable Energy $\left(\mathrm{TME}_{\mathrm{n}}\right)$ were measured by using the calculation method of Sibbald (1986).

Animals were treated ethically in compliance with the local regulations of University of Tehran, Faculty of Veterinary Medicine.

Tissue sampling and preparation of specimens for histomorphometric study: At the end of the experiment, all animals sacrificed by cervical translocation. Whole small intestine removed immediately and immersed in $10 \%$ buffered formalin. After fixation, $1 \mathrm{~cm}$-thick samples were taken from the middle parts of duodenum, jejunum and ileum. The intestinal segmentation was according to the Samanya and Yamauchi (2002) as duodenum (from the gizzard to pancreatic and bile duct), jejunum (from the bile duct to Meckel's diverticulum) and ileum (from the Meckel's diverticulum to ileo-cecalcolonic junction). Routine histological laboratory methods including dehydration, clearing and paraffin embedding used and paraffin blocks made.

Table 1: Composition of basal diet

\begin{tabular}{lc}
\hline Composition & Percentage \\
\hline Corn & 50.00 \\
Wheat & 13.00 \\
Soybeen & 20.00 \\
Barley & 7.40 \\
Vitaminn $^{\mathrm{a}}$ & 0.25 \\
Minerals $^{\mathrm{b}}$ & 0.25 \\
Dicalcium Phosphate & 1.70 \\
Salt & 0.30 \\
Shell & 7.00 \\
DL-Methionin & 0.10 \\
\hline
\end{tabular}

${ }^{a}$ : The vitamin supplied per $2.5 \mathrm{~kg}$ premix: Vitamin A: $9500000 \mathrm{IU}$; Vitamin $\mathrm{D}_{3}$ : $2000000 \mathrm{IU}$; Vitamin E: $18000 \mathrm{IU}$; Vitamin $\mathrm{K}_{3}: 2000$ mg; Vitamin $B_{6}: 3000 \mathrm{mg}$; Vitamin $\mathrm{B}_{9} 1000 \mathrm{mg}$; Vitamin $\mathrm{B}_{12}: 15 \mathrm{mg}$; Vitamin $B_{1}: 1800$ mg; Biotin: 100 mg; Vitamin $B_{2}: 6600$ mg; Vitamin $\mathrm{B}_{3}: 10000 \mathrm{mg}$; Vitamin $\mathrm{B}_{5}: 30000 \mathrm{mg}$; Cholin Chloride: $250000 \mathrm{mg}$. ${ }^{\mathrm{b}}$ The mineral supplied per $2.5 \mathrm{~kg}$ premix : Mn: $100000 \mathrm{mg}$; I: 1000 mg; Fe: 50000 mg; Se: 200 mg; Zn: 100000 mg; Cholin Chloride: $250000 \mathrm{mg}$; $\mathrm{Cu}: 10000 \mathrm{mg}$ 
American J. Animal \& Vet. Sci., 6 (4): 171-175, 2011

About $6 \mu \mathrm{m}$-thick transverse cross-sections were made by a rotary microtome, a total number of 10 slides used from each intestinal segment of each bird; 5 of them stained with HandE for measuring length and width of villi and depth of crypts by using a linear graticule and the remained 5 slides stained with PAS to count goblet cell number per unit area by a 25 latticed graticule under light microscope. Villus length, villus width, crypt depth and goblet cell number per unit area were measured as the arithmetic mean of 15 measurements of each parameter per slide.

Statistical analysis: All data were expressed as mean \pm SD. Data comparisons among groups performed by student's $t$ test and considered statistically significant at $\mathrm{p}<0.05$.

\section{RESULTS}

Body weight: No significant difference observed in body weight of birds from experimental and control groups during the experiment (data not shown).

Chemical composition and metabolizable energy content of sunflower meal and basal diets: Chemical composition and metabolizable energy content of sunflower meal and basal diet are presented in Table 2.

Crude fiber and crude protein of sunflower meal were 81 and $44 \%$ higher than basal diet respectively, while both AME and TME were about $40 \%$ lower in sun flower meal compared to basal diet. No significant difference observed between $\mathrm{AME}$ and $\mathrm{AME}_{\mathrm{n}}$ or TME and $\mathrm{TME}_{\mathrm{n}}$ in both diets.

Histological evaluation of different parts of small intestinal mucosa: In duodenum, villus length and villus length/crypt depth ratio decreased 16 and $27 \%$ with $\mathrm{p}=0.001$ and $\mathrm{p}=0.005$ respectively, while number of goblet cells per unit area increased $50 \%$ in birds fed with sunflower meal single diet compared to basal diet $(p=0.012)$.

The only significant change observed in jejunum of sunflower meal fed birds was $50 \%$ increase in goblet cell number $(\mathrm{p}<0.001)$.

There were $36.5 \%$ decrease in villus length, $20 \%$ decrease in villus width and $40 \%$ decrease in villus length/crypt depth ratio in ileum of sunflower meal fed birds compared to basal diet fed birds with $p<0.001$, $p=0.001$ and $p<0.001$ respectively. Goblet cell number per unit area of ileum increased $20 \%$ in birds fed with sun flower meal diet in comparison with basal diet fed birds $(\mathrm{p} \leq 0.001)$.
Table 2: Chemical composition and metabolizable energy content of sun flower meal and basal diet

\begin{tabular}{|c|c|c|}
\hline Nutrients & Basal diet & Sun flower meal \\
\hline Dry matter (\%) & 93.10 & 94.80 \\
\hline Crude Fiber (\%) & 4.80 & 25.60 \\
\hline Crude Protein $(\%)$ & 17.40 & 31.20 \\
\hline Crude Fat $(\%)$ & 1.00 & 1.00 \\
\hline $\operatorname{Ash}(\%)$ & 11.10 & 7.10 \\
\hline $\operatorname{AME}(\mathrm{Kcal} / \mathrm{kg})$ & 2938.33 & 1753.79 \\
\hline $\mathrm{AME}_{\mathrm{n}}(\mathrm{Kcal} / \mathrm{kg})$ & 2938.26 & 1753.81 \\
\hline TME(Kcal/kg) & 2975.08 & 1804.61 \\
\hline $\mathrm{TME}_{\mathrm{n}}(\mathrm{Kcal} / \mathrm{kg})$ & 2974.99 & 1804.61 \\
\hline
\end{tabular}

Results of histological evaluation of different parts of small intestinal mucosa are summarized in Table 3.

\section{DISCUSSION}

Diet composition is a major factor that can alter the histological status of gut. Nutritionists usually avoid high fiber ingredients in poultry diets because they have low energy values. High levels of fiber also reduce the time of feed passage throughout the digestive system (Johnson, 1981). Furthermore, fiber may cause abrasion of the intestinal mucosa and thus increase the amino acid requirements for the synthesis of mucosal cells (Parsons et al., 1983).

The present study was conducted to clarify possible effects of high fiber sunflower meal single diet on morphological characters of duodenum, jejunum and ileum of adult cocks. In general, health condition of birds was satisfactory throughout the experiment and despite this fact that fiber content of sun flower meal single feed was far exceeding while its TME and AME values were lower than what is used in practice; no significant difference observed in body weight of birds from experimental and control groups, although this observation may be due to the short term of experiment or birds may have compensated low dietary energy levels by adjusting their feed intake, which was not evaluated in the present study. Moreover; $\mathrm{AME}$ and $\mathrm{AME}_{\mathrm{n}}$ as well as $\mathrm{TME}$ and $\mathrm{TME}_{\mathrm{n}}$ values of sunflower meal diet were almost the same which implies that birds in this group did not suffer from a negative nitrogen balance.

Morphological observations of small intestinal epithelium of birds fed with sunflower meal single diet indicated changes compared with birds fed with basal diet. These changes were mostly profound in ileum and all histomorphometric parameters, except crypt depth changed significantly in this part, while there were least changes in jejunum, where maximum digestion and absorption takes place because of large luminal site and presence of more mature enterocytes (Samanta et al., 2010). 
American J. Animal \& Vet. Sci., 6 (4): 171-175, 2011

Table 3: Histological measurements of duodenal, jejunal and ileal wall in Control Group (CG) or Experimental Group (EG)

\begin{tabular}{|c|c|c|c|c|c|c|}
\hline \multirow[b]{2}{*}{ Parameters } & \multicolumn{2}{|l|}{ Duodenum } & \multicolumn{2}{|l|}{ Jejunum } & \multicolumn{2}{|l|}{ Ileum } \\
\hline & $\mathrm{CG}$ & EG & $\mathrm{CG}$ & EG & $\mathrm{CG}$ & EG \\
\hline villus length $(\mu \mathrm{m})$ & $1060 \pm 21$ & $890 \pm 160^{*}$ & $790 \pm 120$ & $810 \pm 170$ & $1040 \pm 250$ & $660 \pm 110^{*}$ \\
\hline villus width $(\mu \mathrm{m})$ & $160 \pm 40$ & $160 \pm 50$ & $120 \pm 30$ & $130 \pm 30$ & $150 \pm 40$ & $120 \pm 20 *$ \\
\hline Crypt depth $(\mu \mathrm{m})$ & $130 \pm 30$ & $140 \pm 40$ & $120 \pm 30$ & $130 \pm 50$ & $120 \pm 30$ & $120 \pm 30$ \\
\hline Villus length/crypt depth ratio & $9.25 \pm 4.34$ & $6.75 \pm 1.95 *$ & $7.03 \pm 1.91$ & $7.11 \pm 2.97$ & $9.33 \pm 2.75$ & $5.60 \pm 1.47 *$ \\
\hline Goblet cell number per $\mathrm{mm}^{2}$ & $0.02 \pm 0.01$ & $0.03 \pm 0.02 *$ & $0.02 \pm 0.01$ & $0.04 \pm 0.01 *$ & $0.04 \pm 0.009$ & $0.05 \pm 0.005^{*}$ \\
\hline
\end{tabular}

Data presented as mean \pm SD *: Sign is used to denote significant difference with Control group $(\mathrm{p}<0.05)$

Sunflower meal did not significantly affect crypt depth in all three parts of the small intestine, thus it does not seem that cellular proliferation rate is appreciably influenced, although this may be due to the short term of the experiment.

It has been cleared that the villus length/crypt depth ratio is a valuable criterion for estimating the digestive capacity of the small intestine and decrease in this ratio is considered to be deleterious to digestion and absorption and vice versa (Pluske et al., 1997). Increased villus height and area suggests an increased surface area capable of greater absorption of nutrients (Caspary, 1992; Awad et al., 2006). Moreover, longer villi are associated with activated cell mitosis which can provide higher nutrient absorptive potential (Samanya and Yamauchi 2002 and Onderci et al., 2006). Deeper crypts indicate fast tissue turnover to permit renewal of the villus as needed (Yason et al., 1987). In the present study the obvious decrease observed in villus length/crypt depth ratio in duodenum and ileum was as the net result of significant decrease in villus length which implies villus atrophy due to sunflower meal single diet. Villus atrophy may be due to low metabolizable energy content of sun flower meal single diet as compared to control diet.

It has been suggested that shorter villi relative to crypts' depths have fewer absorptive cells but more secretory cells (Kritchevsky and Bonfield, 1995). This is consistent with the findings of the present study where sun flower meal single feeding significantly increased number of goblet cells per unit area of intestinal mucosa while decreased villus length in duodenum and ileum. Goblet cells are responsible for secretion of mucin that is used for the mucinous lining of the intestinal epithelium. Thus, higher density of goblet cells may result in an increase in the secretion of mucin. Changes in mucin content or the composition of the mucosal surface may decrease nutrient absorption or increase energy requirement for gut maintenance (Langhout et al., 1999).

\section{CONCLUSION}

In conclusion, single feeding with sun flower meal can adversely affect morphological parameters of small intestinal mucosa of cocks, especially in ileum, that can lead to a reduction in the absorption of nutrients.

\section{ACKNOWLEDGEMENT}

Funding for this study was provided by University of Tehran, Faculty of Veterinary Medicine, Tehran, Iran.

\section{REFERENCES}

AOAC, 1990. Official Methods of Analysis. 1st Edn., Association of Official Analytical Chemists, Washington, ISBN-10: 0935584439.

Awad, W.A., J. Bohm, E. Razzazi-Fazeli, K. Ghareeband and J. Zentek, 2006. Effect of addition of a probiotic microorganism to broiler diets contaminated with deoxynivalenol on performance and histological alterations of intestinal villi of broiler chickens. Poult. Sci., 85: 974-979.

Caspary, W.F., 1992. Physiology and pathophysiology of intestinal absorption. Am. J. Clinic. Nut., 55: 2995-3085.

Johnson, L.R., 1981. Physiology of the Gastrointestinal Tract. 1st Edn., Raven Press, New York, ISBN-10: 0890044406, pp: 1492.

Kalmendal, R., K. Elwinger, L. Holm and R. Tauson, 2011. High-fibre sunflower cake affects small intestinal digestion and health in broiler chickens. Br. Poult. Sci., 52: 86-96. DOI: 10.1080/00071668.2010.547843

Kritchevsky, D. and C. Bonfield, 1995. Dietary Fiber in Health and Disease. 1st Edn., Plenum Press, New York, ISBN-10: 0306457032, pp: 325.

Langhout, D.J., J.B. Schutte, P. Vanleeuwen, J. Wiebengaand and S. Tamminga, 1999. Effect of dietary high-and low-methylated citrus pectin on the activity of the ileal microflora and morphology of the small intestinal wall of broiler chicks. Br. Poult. Sci., 40: 340-347. DOI:10.1080/00071669987421 
Onderci, M., N. Sahin, K. Sahin, G. Cikim and A. Aydin, et al., 2006. Efficacy of supplementation of alpha-amylase-producing bacterial culture on the performance, nutrient use and gut morphology of broiler chickens fed a corn-based diet. Poult. Sci., 85: 505-510.

Parsons, C.M., L.M. Potter and R.D. Brown, Jr., 1983. Effects of dietary carbohydrate and of intestinal microflora on excretion of endogenous amino acids by poultry. Poult. Sci., 62: 483-489. PMID: 6302653

Pluske, J.R., D.J. Hampsonand and I.H. Williams, 1997. Factors influencing the structure and function of the small intestine in the weaned pig: a review. Livestock Produ. Sci., 51: 215-236. DOI: 10.1016/S0301-6226(97)00057-2

Rezaei, M. and H. Hafezian, 2007. Use of different levels of high fiber sunflower meal in commercial leghorn type layer diets. Intel. J. Poult. Sci., 6: 431-433.

Samanta, S., S. Haldar and T.K. Ghosh, 2010. Comparative Efficacy of an Organic Acid Blend and Bacitracin Methylene Disalicylate as Growth Promoters in Broiler Chickens: Effects on Performance, Gut Histology and Small Intestinal Milieu. Vet. Med. Int., 2010: 1-8. DOI: $10.4061 / 2010 / 645150$
Samanya, M. and K. Yamauchi, 2002. Histological alterations of intestinal villi in chickens fed dried Bacillus subtilis var. natto. Comp. Bioch. Physiol.Part A: Mol. Integ. Physiol., 133: 95-104. DOI: 10.1016/S1095-6433(02)00121-6

Senkoylu, N. and N. Dale, 1999. Sunflower meal in poultry diets: A review. World Poult. Sci. J., 55: 153-174.

Sibbald, I.R., 1986. The T.M.E. system of feed evaluation: Methodology, Feed Composition Data and Bibliography. Agriculture Canada. Research Branch, Ottawa, ISBN-10: 066214628X, pp: 114.

Vieira, S.L., A.M. Penz, Jr., E.M. Leboute and J. Corteline, 1992. A nutritional evaluation of a high fiber sunflower meal. J. Applied Poult. Res., 1: 382-388.

Yason, C.V., B.A. Summers and K.A. Schat, 1987. Pathogenesis of rotavirus infection in various age groups of chickens and turkeys: Pathology. Am. J. Vet. Res., 48: 927-938. PMID: 3605809 